\title{
Aspects of Palliative Care Nursing in the Time of COVID-19
}

Aspectos de la enfermería en cuidados paliativos en los tiempos de la COVID-19

Aspectos da enfermagem em cuidados paliativos no contexto da covid-19

Clare Butt ${ }^{1}$

KEYWORDS (SOURCE: DeCS)

Coronavirus infections; pandemic; stress; physiological stress; hospice and palliative care nursing; quality of life.

PALABRAS CLAVE (Fuente: DeCS)

Infecciones por coronavirus; pandemias; estrés; estrés fisiológico; enfermería de cuidados paliativos al final de la vida; calidad de vida.

PALAVRAS-CHAVE (Fonte: DeCS)

Infecções por coronavirus; pandemias; estresse; estresse fisiológico; enfermagem de cuidados paliativos na terminalidade da vida; qualidade de vida.

DOI: 10.5294/aqui.2021.21.1.1

Para citar este editorial / To reference this editorial / Para citar este editorial

Butt C. Aspects of Palliative Care Nursing in the Time of COVID-19. Aquichan, 2021;21(1):e21ll. D0I: https://doi.org/10.5294/aqui.2021.21.1.1

1 https://orcid.org/0000-0002-0214-0379. Sisters of the Holy Family of Nazareth, United States of America. cmbutt@holyfamily.edu 
In this time of a global pandemic, the care of seriously ill patients falls heavily on nurses. Joined with their colleagues in the interdisciplinary team, nurses have the difficult task of providing care in an altered environment. The provision of holistic care is a challenge due to limited time and resources; families may not be able to visit their loved ones, and quality of life suffers for both the patient and the family. Perhaps as never before, the provision of palliative care is highlighted as essential. Additionally, despite enormous stress, nurses can continue caring for others only when they take the time to care for themselves.

\section{Care for patients with COVID-19}

During this global pandemic, the care of seriously ill patients and loved ones who cannot be present falls more heavily on nurses than on other healthcare workers. The increased volume and acuity of patients in hospitals and other healthcare settings have been unprecedented during the coronavirus pandemic. Even for seasoned nurses, caring for ventilated patients suffering from blood clots and other complications is challenging. In addition, patients require multiple medications, which change as the science advances quickly, and families may not be permitted to visit their loved ones.

As a consequence, nurses may be overcome with grief due to the loss of patients, family members, and even fellow nurses. According to the World Health Organization, around $14 \%$ of COVID-19 cases reported to WHO are among healthcare workers (1). How do nurse educators and administrators prepare nurses to not only survive but also to remain compassionate in this environment? Palliative care skills may be the key.

\section{Palliative care}

According to the World Health Organization (2), "Palliative care is an approach that improves the quality of life of patients (adults and children) and their families who are facing problems associated with life-threatening illness. It prevents and relieves suffering through the early identification, correct assessment and treatment of pain and other problems, whether physical, psychosocial or spiritual." Palliative care skills can be taught to nurses in order to address the pressing needs of patients and families precipitated by the coronavirus pandemic. Rosa et al. state, "Palliative care-now more than ever-should be integrated into mainstream health care delivery and further up- stream in the illness process to ensure all frontline providers have a degree of comfort managing symptoms, communicating empathically, and guiding important care discussions in a time of high stress and uncertainty" (3 p262).

\section{Palliative care is holistic}

"Since palliative care is holistic in nature, it is provided by a team of physicians, advanced practice registered nurses, physician assistants, nurses, social workers, and chaplains" (4 p1685). Because nurses have the difficult task of providing care in the altered environment of the pandemic, the palliative care skills of addressing physical, psychosocial, and spiritual needs are essential. Palliative care skills include addressing physical symptoms, such as pain and nausea; psychosocial symptoms, such as anxiety and delirium; spiritual symptoms, such as moral distress and communication difficulties; and end-of-life symptoms, such as dyspnea and terminal secretions. While the provision of holistic care is a challenge due to limited time and resources, palliative care skills can assist nurses in addressing patient and family needs more effectively and efficiently.

\section{Palliative care focuses on the patient and the family}

At a time when families may not be able to visit their loved ones, palliative care skills offer ways to address the needs of both the patient and the family (4). Besides focusing on assessing and managing pain and other patient symptoms, palliative care skills help nurses assess and support families and coordinate communication, even remotely during these times. Nurses can work closely with other team members to ensure a continuous dialogue with family members, including timely updates about the patient's condition and assessing how the family is coping with separation and grief. This can help build trust, improve communication, and minimize family distress.

\section{Palliative care improves quality of life}

During the pandemic, quality of life is compromised for both the patient and the family. Through early integration into the care of the seriously ill patient, nurses can use palliative care skills to improve the quality of life for both the patient and the family 
by preventing and relieving suffering. With a comprehensive assessment, the nurse can develop and implement a care plan that respects patient and family values, goals, and beliefs, assuring the best quality of life for patients and their families.

When the time comes for end-of-life patient care, palliative care nursing skills are especially needed. According to Dobratz, "Psychological adaptation in death and dying is using spiritual and social resources, and managing physical symptoms to maintain selfintegration" (5 p373). The author names three theoretical assumptions for psychological adaptation at the end-of-life. Psychological adaptation in death and dying is 1 ) influenced by pain and physical function; 2) promoted by connecting to supportive others, and 3) influenced by spirituality. Therefore, the palliative care skills of nurses are valuable in supporting quality of life when death is near.

\section{Nurses need to care for themselves during the COVID-19 crisis}

There are consequences to the stress and trauma experienced by nurses when caring for patients and families during the coronavirus pandemic. In addition to acute care settings, palliative care may be delivered in patient homes and other community settings (4). The World Health Organization reports that "the pandemic has placed extraordinary levels of psychological stress on health workers exposed to high-demand settings for long hours, living in constant fear of disease exposure while separated from family and facing social stigmatization" (1). Educators and administrators need to be proactive in providing support to nurses and other healthcare workers because their well-being directly affects the well-being of patients and families. Rosa et al. (3) offer some suggestions for nurses during the COVID-19 pandemic, focusing on improved education, communication, teamwork, and mental health support. Particularly for new or student nurses, they advise training related to the ability to lead goals of care and ethical discussions; knowledge of institutional resources to educate patients/families on various levels of care for the patient, and keeping informed about research related to likely outcomes for patients who test positive for COVID-19. May the tireless efforts of all, including educators, administrators, and researchers, work together to support nurses during these unusual times.

\section{References}

1. World Health Organization. Keep health workers safe to keep patients safe: WHO. (September 17, 2020) https://www. who.int/news-room/detail/17-09-2020-keep-health-workers-safe-to-keep-patients-safe-who

2. World Health Organization. Palliative care fact sheet. (August 5, 2020). https://www.who.int/news-room/fact-sheets/ detail/palliative-care

3. Rosa WE, Gray TF, Chow K, Davidson PM, Dionne-Odom JN, Karanja V, et al. Recommendations to leverage the palliative nursing role during COVID-19 and future public health crises. J Hosp Palliat Nurs. 2020;22(4),260-9. DOI: https://doi. org/10.1097/njh.0000000000000665

4. Ferrel BR, Twaddle ML, Melnick A, Meier DE. National Consensus Project Clinical Practice Guidelines for Quality Palliative Care Guidelines, 4th Edition. J Pall Med. 2018;21(12);1684-9. DOI: https://doi.org/10.1089/jpm.2018.0431

5. Dobratz, M. Toward development of a middle-range theory of psychological adaptation in death and dying. Nurs Sci Q. 2011;24(4):370-6. DOI: https://doi.org/10.1177/0894318411419212 